\title{
Research on Retailer's Financial and Operation Decisions Based on Strategic Customer
}

\author{
LIU Heng \\ Department of Economics and Management \\ HUIZHOU University \\ Huizhou, China, 13824243976 \\ Liuheng73@163.com
}

\begin{abstract}
This paper studies retailer's decision and financial institution's decision based on the strategic customer when retailer accepts financial service from financial institutions. Research shows that financing rate increases with the wholesale price and the average rate of return on investment increasing and decreases with the retailer's own funds increasing, and retailer's ordering quantity with finance service is higher than that of without finance service, and retailer and financial institution both get more the expected profit, and strategic customers get more benefits. Finall$y$, a numerical example is validated.
\end{abstract}

Keywords- financial services; strategic customer; financing rate

\section{INTRODUCTION}

Since the 2008 financial crisis, many enterprises in supply chain face shortage of fund due to the financial institutions' credit crunch increasing, while financial institutions worry about operation risk caused by excessive loan which affects their income increasing. What supply chain enterprises do to solve the shortage of fund and financial institutions to seek new-growing value point becomes problem to be solved by business circles and academic.

The concept of strategic customer describes the consumer buying behavior in real life ${ }^{[1]}$. Scholars study the strategic customer from different angles. Firstly, it is from the retailer's static or dynamic pricing mechanism. Aviv \& Pazgal (2008) studied a retailer facing strategic customer how to dynamic price, their research shows strategic customer's behavior deprive retailer's additional gains due to part price discrimination ${ }^{[2]}$. Peng Zhi-qiang et al. (2008) results show that customer heterogeneity can influence the service provider's dynamic pricing strategy $^{[3]}$. Peng \& Xiong (2008) studied how retailers to dynamic price facing the strategic customer's valuation is uncertainty based on literature [3], and pointed out that the retailer commitment to customers return can improve the retailers profit expectations $^{[4]}$. Secondly, it is from how to reduce strategic customer waiting behavior. Shen \& Su (2007) pointed out that retailers need to introduce new inventory and price mechanism to reduce strategic customer waiting behavior ${ }^{[5]}$. Thirdly, it is fro$\mathrm{m}$ the symmetry and asymmetry information. Elmaghraby et al. (2008) studied the retailer's optimal price mechanism when the strategic customer's psychological price is complete information and incomplete information ${ }^{[6]}$. These literatures are all assumed that the retailers have sufficient funds at the time of deci- sion making, but not consider that the retailers may have insufficient funds.

As for the supply chain enterprises have a shortage of funds at the time of decision making, business circles and academia have put forward various concepts, such as the supply chain finance, financing warehouse, logistics bank, which are widely used in practice, for example China Material Storage and Transportation Company launched the impawning supervision business in 1999, UPS announced in 2007 that UPS would launch the "UPS Global Supply Chain Finance Scheme" with China Shanghai Pudong Development Bank, Shenzhen Development Bank and China Merchants Bank. Huaxia Bank introduced financial supply chain service brand "win-win financing chain" in 2008. Many scholars also have put forward many solutions ${ }^{[7 \sim 10]}$ Zhou Jian-heng (2010) analyzed financing and repurchases the simultaneous presence of supply chain decision, his results showed that suppliers in supply chain can coordination order quantity through the buy-back contract, the whole supply chain performance improved compared with that of without loans when bank loans to retailers ${ }^{[11]}$. The above literatures do not consider strategic customer in supply chain.

Based on literature [10], this paper studies the optimal strategy for the retailer's decision and the financial institution's decision based on strategic customer when the retailer has fund shortage. The contribution of this paper is focused on two aspects: (1) the optimal strategy for the retailer's decision and the financial institution's decision based on strategic customer without financing service; (2) the optimal strategy for the retailer decision and the financial institution's decision based on strategic customer with financing service, we reveal how the strategic customer consumption behavior and the shortage of fund effect on the enterprise operating and financial institutions. Results shows that financing rate increases with wholesale price and the average rate of return on investment in capital market increasing and with retailer's own fund decreasing; retailer's ordering quantity is higher, the expected profit of retailer and financial institution are larger, strategic customers get more benefits than that with no-financing service. These are consistent with the actual situation.

\section{MODEL ASSUMPTION}

We assume a supplier offers $Q$ unit single product to retailer with fixed wholesale price $w$. Retailer in the procurement process has its own fund $B$ for the procurement. Market demand 
is uncertain, its density function is $f(D)$, cumulative distribution function is $F(D)$ which is guide and continuous, strictly increaseing, and $\bar{F}(D)=1-F(D)$. Before the sales cycle starts, the retailer who has insufficient fund can get financing service $w Q$ $B$ from financial institution in the competition of capital market financing service to order goods quantity; then the retailer has to fixed retail price $p$ facing the homogeneous strategic customer whose consumer utility is $U^{c o n}$. At the end of the sales cycle, the retailer pay back for financial institution's financing service $L_{l}=\min [p \min [D, Q],(w Q-B)(1+r)]$, which $r$ is financing rate. Consumer is strategic customers. $\psi$ is the consumer psychologycal price. $\xi_{\text {prob }}$ is the probability which the consumers within product processing buy the product, $\xi_{\psi}$ is the estimated consum-er psychological price. Superscript $R$ notes the retailer. $\pi$ is the retailer's expected profit. * is the optimal strategy.

For the convenience of study, this paper assumes that the product salvage value is zero. Retailer has optimal strategy.

\section{THE OPTIMAL STRATEGY OF RETAILER AND FINANCIAL INSTITUTION}

Retailer facing a shortage of fund has two choices, one is not accept financing from or apply to financial institutions, the other is financing from financial institutions. From realistic point of view, the retailer based on maximization of his own interests chooses whether to accept financing from or apply to financial institutions, namely, retailer's profit with financing from financial institution is at least equal to that with no-financing. In either case, price strategy game is made between retailer and customer.

\section{A. Price Game between Retailer and Strategy Customer}

According to the literature [12] conclusion, during the sale season, if the retail price meet to $U^{c o n}-p \geq U^{c o n} \xi_{p r o b}$, strategic customer will buy product from retailer immediately instead of waiting. The price equilibrium condition between strategic customer and retailer is as follow

$$
\left\{\begin{array}{l}
p=U^{c o n}-U^{c o n} \xi_{p r o b} \\
p=\xi_{\psi} \\
Q=\arg \max _{Q} E\left(\pi^{R}(Q)\right) \\
\xi_{\text {prob }}=F(Q) \\
\xi_{\psi}=\psi
\end{array}\right.
$$

We simplify formula (1) as follow

$$
\left\{\begin{array}{c}
p=U^{\text {con }} \bar{F}(Q) \\
Q=\arg \max _{Q} E\left(\pi^{R}(Q)\right)
\end{array}\right.
$$

Formula (2) describes the retail price $p$ is a function of order quantity $Q$.

After the price game between retailer and strategic customer, retailer needs to decide whether to finance from financial institution according to his own fund. If the retailer decides to apply to financial institution, financial institution needs to decide the financing rate.

\section{B. Financial Institution's Financing Rate Policy}

During the sale season, the average market investment rate of return in competitive capital market $r_{f}$ can be viewed as a fixed numerical value. As long as the retailer applies for financing, the financial institution's expected return is equal to the average investment return in capital market which is (wQ$B)\left(1+r_{f}\right), r \geq r_{f}$. Financing rate satisfies

$$
\int_{0}^{z} p x f(x) d x+\int_{z}^{+\infty} p z f(x) d x=(w Q-B)\left(1+r_{f}\right)
$$

which $z=\frac{(w Q-B)(1+r)}{p}$ is the profit and loss balance $\mathrm{p}$ oint of financial institution.

For formula (3), there are two cases:

(I) if the financing institution only knows the retail price and order quantity, respectively, and do not know the relationnship between retail price and order quantity, then the financeing institution's financing rates can be calculated according to proposition 1 in literature [10];

(II) if the financing institution know the retail price $p$ and order quantity $Q$, respectively, and do know the relationship between retail price and order quantity, $p(Q)$. $z$ is rewritten as $z=\frac{(w Q-B)(1+r)}{U^{c o n} \bar{F}(Q)}$.

Since this paper concerns strategic customer, so we dismiss the case (I) and discuss the case (II).

Substituting the formula (2) into formula (3), we get $r^{*}\left(U^{c o n}, w, Q, r_{f}\right)$ and $z^{*}\left(r^{*}\left(U^{c o n}, w, Q, r_{f}\right)\right)$.

Theorem 1 Financing rate $r^{*}$ increases with the wholesale price and the average rate of return on investment in capital market increasing, and decreases with retailer's own fund increaseing.

Proof: From formula (3), we have

$$
\left(1+r_{f}\right)-\left(1+r^{*}\right) \bar{F}\left(\frac{(w Q-B)\left(1+r^{*}\right)}{U^{c o n} \bar{F}(Q)}\right)>0 .
$$

We define $H=U^{\text {con }} \bar{F}(Q) G$, which

$$
\begin{aligned}
G= & \int_{0}^{\frac{(w Q-B)\left(1+r^{*}\right)}{U^{c o n} \bar{F}(Q)}} x f(x) d x+\frac{(w Q-B)\left(1+r^{*}\right)}{U^{c o n} \bar{F}(Q)} \int_{\frac{(w Q-B)\left(1+r^{*}\right)}{U^{c o n} \bar{F}(Q)}}^{+\infty} f(x) d x- \\
& \frac{(w Q-B)\left(1+r_{f}\right)}{U^{c o n} \bar{F}(Q)}
\end{aligned}
$$

By taking $G$ partial derivative for $B, w, r^{*}$ and $r_{f}$, respectively, and we get 


$$
\begin{gathered}
\frac{\partial G}{\partial B}=\frac{1}{U^{c o n} \bar{F}(Q)}\left(\left(1+r_{f}\right)-\left(1+r^{*}\right) \bar{F}\left(\frac{(w Q-B)\left(1+r^{*}\right)}{U^{c o n} \bar{F}(Q)}\right)\right)>0 \\
\frac{\partial H}{\partial B}=U^{c o n} \bar{F}(Q) \frac{\partial G}{\partial B}>0 \\
\frac{\partial G}{\partial w}=Q \frac{\left(1+r^{*}\right) \int_{\frac{(w Q-B)\left(1+r^{*}\right)}{U^{c o n} \bar{F}(Q)}}^{+\infty} f(x) d x-\left(1+r_{f}\right)}{U^{c o n} \bar{F}(Q)}<0 \\
\frac{\partial H}{\partial w}=U^{c o n} \bar{F}(Q) \frac{\partial G}{\partial w}<0 \\
\frac{\partial G}{\partial r^{*}}=\frac{w Q-B}{U^{c o n} \bar{F}(Q)} \bar{F}\left(\frac{(w Q-B)\left(1+r^{*}\right)}{U^{c o n} \bar{F}(Q)}\right)>0 \\
\frac{\partial H}{\partial r^{*}}=U^{c o n} \bar{F}(Q) \frac{\partial G}{\partial r^{*}}>0, \frac{\partial G}{\partial r_{f}}=-\frac{w Q-B}{U^{c o n} \bar{F}(Q)}<0 \\
\frac{\partial H}{\partial r_{f}}=U^{c o n} \bar{F}(Q) \frac{\partial G}{\partial r_{f}}<0
\end{gathered}
$$

Then we have

$$
\begin{gathered}
\frac{\partial r^{*}}{\partial B}=-\frac{\partial H / \partial B}{\partial H / \partial r^{*}}=-\frac{\left(1+r_{f}\right)-\left(1+r^{*}\right) \bar{F}\left(\frac{(w Q-B)\left(1+r^{*}\right)}{U^{c o n} \bar{F}(Q)}\right)}{(w Q-B) \bar{F}\left(\frac{(w Q-B)\left(1+r^{*}\right)}{U^{c o n} \bar{F}(Q)}\right)}<0 \\
\left.\frac{\partial r^{*}}{\partial w}=-\frac{\partial H / \partial w}{\partial H / \partial r^{*}}=-Q \frac{\left(1+r^{*}\right) \int_{\frac{(w Q-B)\left(1+r^{*}\right)}{U^{c o n} \bar{F}(Q)} f(x) d x-\left(1+r_{f}\right)}^{(w Q-B) \bar{F}\left(\frac{(w Q-B)\left(1+r^{*}\right)}{U^{c o n} \bar{F}(Q)}\right)}>0}{\frac{\partial r^{*}}{\partial r_{f}}=-\frac{\partial H / \partial r_{f}}{\partial H / \partial r^{*}}=\frac{1}{\bar{F}\left(\frac{(w Q-B)\left(1+r^{*}\right)}{U^{c o n} \bar{F}(Q)}\right)}>0 . \square}\right)
\end{gathered}
$$

Theorem 2 If $G>0$, then the financing rates decreases with consumer utility increasing, and increases with retailer order quantity increasing.

Proof: By taking $G$ partial derivative for $U^{c o n}$ and $Q$, respectively, we have

$$
\begin{gathered}
\frac{\partial G}{\partial U^{c o n}}=\frac{w Q-B}{\left(U^{c o n}\right)^{2} \bar{F}(Q)}\left(\left(1+r_{f}\right)-\left(1+r^{*}\right) \bar{F}\left(\frac{(w Q-B)\left(1+r^{*}\right)}{U^{c o n} \bar{F}(Q)}\right)\right)>0 \\
\frac{\partial H}{\partial U^{c o n}}=\bar{F}(Q)\left(G+U^{c o n} \frac{\partial G}{\partial U^{c o n}}\right)
\end{gathered}
$$

If $G>0$, then $\frac{\partial H}{\partial U^{c o n}}>0$.

$$
\begin{gathered}
\frac{\partial G}{\partial Q}=\left(\left(1+r^{*}\right) \bar{F}\left(\frac{(w Q-B)\left(1+r^{*}\right)}{U^{c o n} \bar{F}(Q)}\right)-\left(1+r_{f}\right)\right) \times \\
\frac{w \bar{F}(Q)+(w Q-B) f(Q)}{U^{c o n}(\bar{F}(Q))^{2}}<0 \\
\frac{\partial H}{\partial Q}=U^{c o n}\left(-f(Q) G+\bar{F}(Q) \frac{\partial G}{\partial Q}\right)
\end{gathered}
$$

If $G>0$, then $\frac{\partial H}{\partial Q}<0$.

$$
\begin{aligned}
& \frac{\partial G}{\partial r^{*}}=\frac{w Q-B}{U^{c o n} \bar{F}(Q)} \bar{F}\left(\frac{(w Q-B)\left(1+r^{*}\right)}{U^{c o n} \bar{F}(Q)}\right)>0 \\
& \frac{\partial H}{\partial r^{*}}=U^{c o n} \bar{F}(Q) \frac{\partial G}{\partial r^{*}}>0, \frac{\partial r^{*}}{\partial U^{c o n}}=-\frac{\partial H / \partial U^{c o n}}{\partial H / \partial r^{*}}<0, \\
& \frac{\partial r^{*}}{\partial Q}=-\frac{\partial H / \partial Q}{\partial H / \partial r^{*}}>0 .
\end{aligned}
$$

From analysis in case (I) and (II), financial institution in these two cases may make different financing decision, which has the same characteristics with the literature [10].

\section{Retailer's Optimal Order Strategy}

After the retailer receives financing service, if $z \geq Q$ then $(w Q-B) \geq(p-w) Q+B$ which means that retailer's paying back to financial institution is more than his sales profit, the retailer's choice of financing is not possible, so there must have $z<Q$.

After the sales cycle ends, the retailers obtain sales profit is

$$
\Pi^{R}=\left\{\begin{array}{lr}
0, & x \leq z \\
p x-(w Q-B)(1+r), & z<x \leq Q \\
p Q-(w Q-B)(1+r), & x>Q
\end{array}\right.
$$

Retailer's expected profit is

$$
\begin{aligned}
\pi^{R}= & \int_{z}^{O}(p x-(w Q-B)(1+r)) f(x) d x+ \\
& \int_{Q}^{+\infty}(p Q-(w Q-B)(1+r)) f(x) d x
\end{aligned}
$$

We substitute the formula (2) into the formula (5), and then simplify the formula (5) as follow 


$$
\begin{aligned}
& \pi^{R}=U^{c o n}\left(\begin{array}{l}
\int_{z}^{O}(\bar{F}(Q)(x-z)) f(x) d x+ \\
\int_{Q}^{+\infty}(\bar{F}(Q)(Q-z)) f(x) d x
\end{array}\right) \\
& =\bar{F}(Q)\left(\int_{0}^{Q} x f(x) d x+Q \bar{F}(Q)\right)-\frac{(w Q-B)\left(1+r_{f}\right)}{U^{c o n}}
\end{aligned}
$$

By taking $\pi^{R}$ the first derivative for $Q$, and then simplifying, we get

$$
\begin{aligned}
\frac{\partial \pi^{R}}{U^{c o n} \partial Q}= & \bar{F}(Q)\left(\bar{F}(Q)-\left(1+r_{f}\right) \frac{w \bar{F}(Q)+(w Q-B) f(Q)}{U^{c o n}(\bar{F}(Q))^{2}}\right)- \\
& \frac{f(Q) \pi^{R}}{U^{c o n} \bar{F}(Q)}
\end{aligned}
$$

Theorem 3 The retailer's optimal order quantity $Q^{*}$ satisfyies as follow

$$
\begin{aligned}
& \bar{F}\left(Q^{*}\right)\left(\bar{F}\left(Q^{*}\right)-\left(1+r_{f}\right) \frac{w \bar{F}\left(Q^{*}\right)+\left(w Q^{*}-B\right) f\left(Q^{*}\right)}{U^{c o n}\left(\bar{F}\left(Q^{*}\right)\right)^{2}}\right)- \\
& \frac{f\left(Q^{*}\right) \pi^{R}}{U^{c o n} \bar{F}\left(Q^{*}\right)}=0
\end{aligned}
$$

Next, we discuss the characters of retailer's optimal ordering quantity.

We define

$$
M(Q)=\bar{F}(Q)-\frac{\left(1+r_{f}\right)}{U^{c o n}} \frac{w \bar{F}(Q)+(w Q-B) f(Q)}{(\bar{F}(Q))^{2}}
$$

.As for $M(Q)$, we have

$$
\begin{aligned}
& \lim _{Q \rightarrow 0^{+}}(M(Q))=\frac{U^{\text {con }}-\left(1+r_{f}\right)}{U^{c o n}} w>0 \\
& \lim _{Q \rightarrow+\infty}(M(Q))=-\frac{\left(1+r_{f}\right)}{U^{c o n}} \lim _{Q \rightarrow+\infty}\left(\frac{w Q f(Q)}{(\bar{F}(Q))^{2}}\right)<0
\end{aligned}
$$

so there must at least one $Q(>0)$ to satisfy $M(Q)=0$.

It is obviously that the retailer do not have optimal order quantity when $M(Q)<0$ which means $\frac{\partial \pi^{R}}{U^{c o n} \partial Q}<0$ and have at least one optimal order quantity when $M(Q)>0$ which means $\frac{\partial \pi^{R}}{U^{\text {con }} \partial Q}=0$. So we have the theorem 4 .

Theorem 4 The retailer's optimal order quantity satisfies $M\left(Q^{*}\right)=0$.
From theorem 4, we have two corollaries.

Corollary 1 If $r_{f}$ is fixed, we define

$$
U_{\min }^{c o n}=\left(1+r_{f}\right) \frac{w \bar{F}\left(Q^{*}\right)+\left(w Q^{*}-B\right) f\left(Q^{*}\right)}{\left(\bar{F}\left(Q^{*}\right)\right)^{3}}
$$

as the minimum critical value of consumer utility, so it have $U^{c o n}>U_{\min }^{c o n}$.

Corollary 1 shows that based on the price game between the retailers and the strategy of consumer, retailer is needed to pay back the financing cost, from the formula (6), so he must subdivide and lock consumers in the market to enable the consumer utility is greater than the minimum critical value.

Corollary 2 If $U^{c o n}$ is fixed, we define

$$
r_{f \max }=\frac{U^{c o n}\left(\bar{F}\left(Q^{*}\right)\right)^{3}}{w \bar{F}\left(Q^{*}\right)+\left(w Q^{*}-B\right) f\left(Q^{*}\right)}-1
$$

as the maximum critical value of average market investment rate of return in competitive capital market, so it have $r_{\text {fmax }}>r_{f}(>0)$.

Corollary 2 shows the financial institutions can not be unlimited raising financing rate from the visual point of view when the market demand is fixed; otherwise retailer will not apply for financing. Financing rate must be less than maximum critical value of average market investment rate of return in competitive capital market (such as People's Bank of China has similar provisions of the floating interest rates on the Bank in China).

Last, we compare the retailer's optimal order quantity with strategic customer and that with non-strategic customer.When the consumer is non-strategic, we have the retailer's optimal order quantity $\bar{Q}^{*}$ satisfying $\bar{F}\left(\bar{Q}^{*}\right)=\frac{w\left(1+r_{f}\right)}{p}$.

We make $p=U^{c o n}$, then substitute $p=U^{c o n}$ into $\bar{Q}^{*}$, we have $\bar{F}\left(\bar{Q}^{*}\right)=\frac{w\left(1+r_{f}\right)}{U^{c o n}}$ 。We make $Q=\bar{Q}^{*}$, then substitute $Q=\bar{Q}^{*}$ into formula (7). We have

$$
\begin{gathered}
\left.\frac{\partial \pi^{R}}{U^{c o n} \partial Q}\right|_{Q=\bar{Q}^{*}}=\bar{F}\left(\bar{Q}^{*}\right)\left(\begin{array}{l}
-\frac{\left(1+r_{f}\right)}{U^{c o n}} \frac{w \bar{F}\left(\bar{Q}^{*}\right)+\left(w \bar{Q}^{*}-B\right) f\left(\bar{Q}^{*}\right)}{\left(\bar{F}\left(\bar{Q}^{*}\right)\right)^{2}} \\
+\frac{w\left(1+r_{f}\right)}{U^{c o n}}
\end{array}\right)- \\
f\left(\bar{Q}^{*}\right) \frac{\pi^{R}}{U^{c o n} \bar{F}\left(\bar{Q}^{*}\right)}
\end{gathered}
$$

We simplify the above formula and then get 


$$
\begin{gathered}
\left.\frac{\partial \pi^{R}}{U^{c o n} \partial Q}\right|_{Q=\bar{Q}^{*}}=-\bar{F}\left(\bar{Q}^{*}\right) \frac{\left(1+r_{f}\right)}{U^{c o n}}\left(\frac{w F\left(\bar{Q}^{*}\right)}{\bar{F}\left(\bar{Q}^{*}\right)}+\frac{\left(w \bar{Q}^{*}-B\right) f\left(\bar{Q}^{*}\right)}{\left(\bar{F}\left(\bar{Q}^{*}\right)\right)^{2}}\right)- \\
f\left(\bar{Q}^{*}\right) \frac{\pi^{R}}{U^{c o n} \bar{F}\left(\bar{Q}^{*}\right)}<0
\end{gathered}
$$

$\left.\frac{\partial \pi^{R}}{U^{c o n} \partial Q}\right|_{Q=\bar{Q}^{*}}<0$ which means the retailer's optimal order quantity with strategic consumer is lower than that with nonstrategic consumer. Thus we have the theorem 5.

Theorem 5 The retailer's optimal order quantity with strategic customer is lower than that with non-strategic customer.

\section{CASE EXAMPLE}

We use a numerical example to illustrate our results. We assume $D \in U[0,1000], w=13, r_{f}=0.03 . U^{c o n}$ is $20,25,30,35$, 40. $B$ is $600,1000,1500,2000$ and 2200.

We first calculate the retailer's optimal decision without financial service. The retailer's expected profit and optimal ordering quantity are shown in Figure 1 and Table 1, respectively.

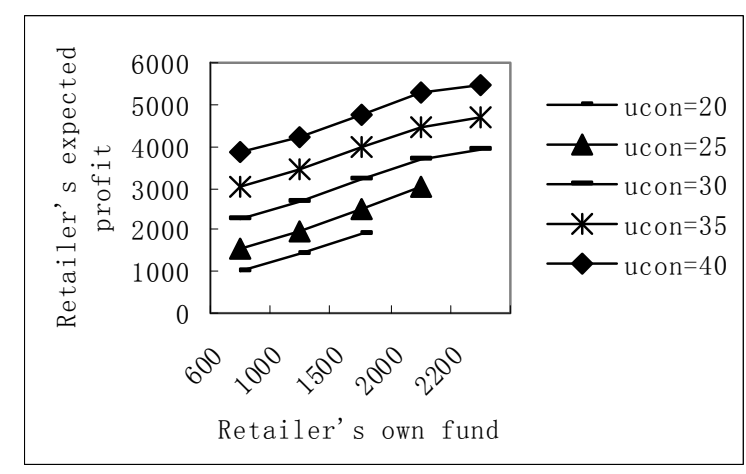

Figure 1. The Retailer's Expected Profit without Financial Service

Figure 1 illustrates that the retailer's expected profit increases with retailer's own fund increasing when consumer utility fixed.

We then calculate the retailer's optimal decision and financial institution decision with financial service. The optimal ordering quantity is shown in Table 1.

TABLE I. 1 THE OPTIMAL ORDERING QUANTITY

\begin{tabular}{|c|c|c|c|}
\hline $\boldsymbol{U}^{\text {con }}$ & without financial service & with financial service & $\boldsymbol{B}$ \\
\hline 20 & 46 & 117 & 600 \\
\hline 20 & 76 & 117 & 1000 \\
\hline 20 & 115 & 117 & 1500 \\
\hline 20 & 124 & 154 & 2000 \\
\hline 20 & 124 & 170 & 2200 \\
\hline 25 & 46 & 169 & 600 \\
\hline 25 & 76 & 169 & 1000 \\
\hline 25 & 115 & 169 & 1500 \\
\hline
\end{tabular}

\begin{tabular}{|c|c|c|c|}
25 & 153 & 169 & 2000 \\
\hline 25 & 169 & 170 & 2200 \\
\hline 30 & 46 & 206 & 600 \\
\hline 30 & 76 & 206 & 1000 \\
\hline 30 & 115 & 206 & 1500 \\
\hline 30 & 153 & 206 & 2000 \\
\hline 30 & 169 & 206 & 2200 \\
\hline 35 & 46 & 233 & 600 \\
\hline 35 & 76 & 233 & 1000 \\
\hline 35 & 115 & 233 & 1500 \\
\hline 35 & 153 & 233 & 2000 \\
\hline 35 & 169 & 233 & 2200 \\
\hline 40 & 46 & 206 & 600 \\
\hline 40 & 76 & 206 & 1000 \\
\hline 40 & 115 & 206 & 1500 \\
\hline 40 & 153 & 206 & 2000 \\
\hline 40 & 169 & 206 & 2200 \\
\hline
\end{tabular}

From Table 1, we can see that the optimal ordering quantity with financial service is larger than that of without financial service, and at least more than $B / w$.

The financing rate is shown in Figure 2.

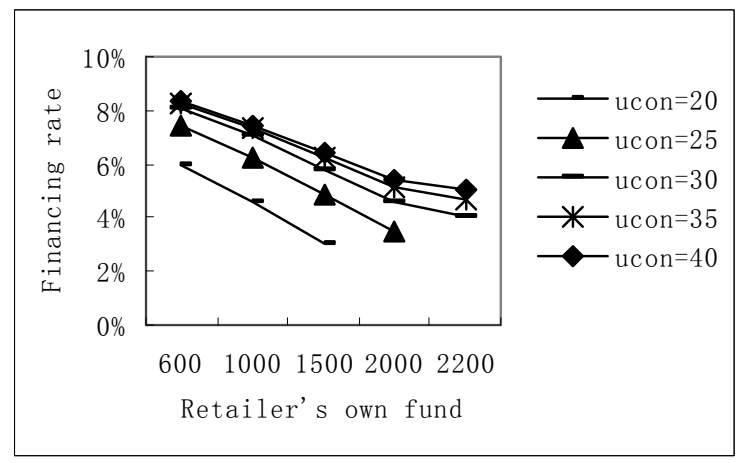

Figure 2. The Financing Rate with Financial Service

Figure 2 illustrates that the financing rate increases with consumer utility increasing when retailer's own fund is fixed and that the financing rate decreases with retailer's own fund increasing when consumer utility fixed.

The retailer's expected profit is shown in Figure 3. 


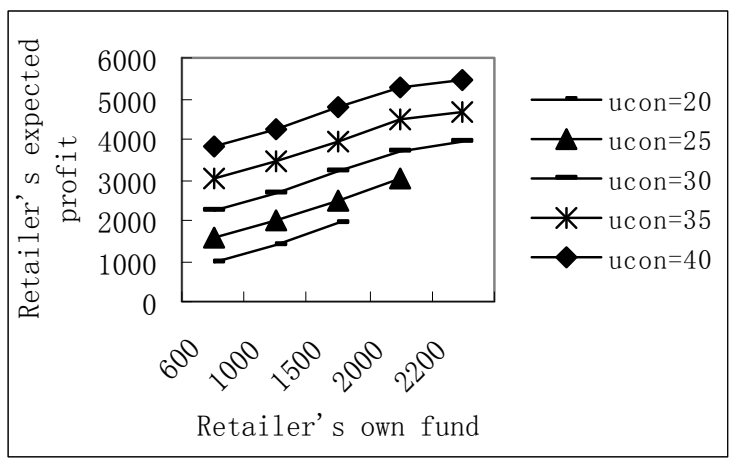

Figure 3. The Retailer's Expected Profit with Financial Service

Figure 3 illustrates that the retailer's expected profit increases with consumer utility increasing when retailer's own fund is fixed and that the retailer's expected profit increases with retailer's own fund increasing when consumer utility fixed.

The financial institution's expected profit is shown in Figure 4.

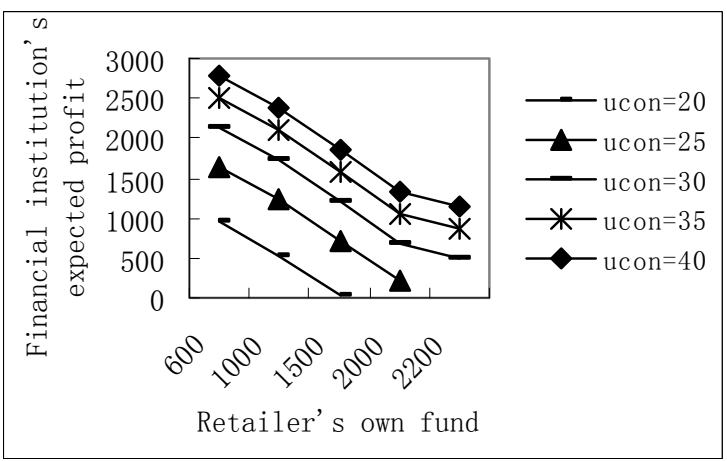

Figure 4. The Financial Institution's Expected Profit with Financial Service

Figure 4 illustrates that the financial institution's expected profit increases with consumer utility increasing when retailer's own fund is fixed and that he financial institution's expected profit decreases with retailer's own fund increasing when consumer utility fixed.

\section{CONCLUSION}

This paper studies retailer's decision and financial institution's decision based on the strategic customer when retailer accepts financial service from financial institutions. Research shows that financing rate increases with the wholesale price and the average rate of return on investment increasing and decreases with the retailer's own funds increasing; retailer's order- ing quantity with finance service is higher than that of without finance service; retailer and financial institution both get more the expected profit; strategic customers get more benefits. Finally, a numerical example is validated.

In future research, as the literature [10] pointed out "the hypotheses of capital market financing services provide financial institutions are risk neutral, if the change of this hypothesis have different conclusions", therefore, risk-preference financial institution's decision behavior is the next research direction. Then, how a risk-preference decision maker of financial institution and risk preference of decision makers of supply chain influences on the operation of supply chain and financial institution is the further research direction.

\section{REFERENCES}

[1] R. Coase, "Durability and monopoly," Journal of Law and Economics, 1972, 15, pp. 143-149.

[2] Y. Aviv, A. Pazgal, "Optimal pricing of seasonal products in the presence of forward-looking consumers," Manufacturing \& Service Operations Management, 2008, vol. 10, No. 3, pp. 339-359.

[3] Peng Zhi-qiang, Xiong Zhong-kai, Li Hao, "Service providers pricing strategy based on customer pricing model," Statistics and Decision, 2008, vol. 273, No. 21, pp. 169-171 (In Chinese).

[4] Z. Peng, Y. Xiong, "Value uncertain in advance selling: The impact of offering refunds for cancellations," International Conference on Service Operations and Logistics, and Informatics, Beijing, China, IEEE, 2008: 64-68.

[5] Z. Shen, X. Su, "Customer behavior modeling in revenue management and auctions: A review and new research opportunities," Production and Operations Management, 2007, vol. 16, No. 6, pp. 713-728.

[6] W. Elmaghraby, A. Gülcü, P. Keskinocak, "Designing optimal preannounced markdowns in the presence of rational customers with multiunit demands," Manufacturing \& Service Operations Management, 2008, vol. 10, No.1, pp. 126-148.

[7] ZHU Wen-gui, ZHU Dao-li, XU Zui, "Pricing model for inventory impawn financing under conditions of permissible delay in payments," Systems Engineering-Theory \& Practice, 2007, vol. 12, pp. 1-7 (In Chinese).

[8] G. Z. Feng, "Analysis of logistics financing business innovation," Forecasting, 2007, vol. 26, No. 1, pp. 49-54 (In Chinese).

[9] LI Yi-xue, FENG Geng-zhong, XU Yu, "Research On Loan-to-value Ratio of Inventory Financing under Randomly-fluctuant Price," Systems Engineering-Theory \& Practice, 2007, No. 12, pp. 42-48 (In Chinese).

[10] CHEN Xiang-feng, ZHU Dao-li, YING Wen-jun, "Financial and operation decisions in budget-constrained supply chain," Journal of Management Sciences in China, 2008, vol. 11, No. 3, pp. 70-77 (In Chinese).

[11] Zhou Jian-heng, "Analysis of financing and buy-back decision making in a supply chain," Industrial Engineering Journal, 2010, vol. 13, No. 3, pp. 25-28 (In Chinese).

[12] X. Su, F. Zhang, "Strategic customer behavior, commitment, and supply chain performance," Management Science, 2008, vol. 54, No. 10, pp. 1759-1773. 